\title{
Proteinograma sérico, com ênfase em proteínas de fase aguda, de bovinos sadios e bovinos portadores de enfermidade aguda de ocorrência natural
}

[Serum proteinogram emphasizing acute phase proteins from healthy and acute naturally occurring diseased cattle]

K.M.M.G. Simplício, F.C. Sousa, J.J. Fagliari, P.C. Silva

Faculdade de Ciências Agrárias e Veterinárias - Universidade Estadual Paulista - Unesp - Jaboticabal, SP

\section{RESUMO}

Nas últimas décadas, as proteínas de fase aguda (PFAs) tornaram-se biomarcadores de escolha em medicina humana para identificação e monitoração de doenças. Não há razão para imaginar que tais pesquisas clínicas não sejam igualmente úteis na medicina veterinária. Com o objetivo de verificar a importância das PFAs como biomarcadores de doenças inflamatórias em bovinos, determinou-se o proteinograma sérico, por meio da técnica de eletroforese SDS-PAGE, com interesse especial nas PFAs. Foram utilizados 30 animais, distribuídos em dois grupos: 15 bovinos sadios e 15 bovinos doentes (cinco com mastite estafilocócica, cinco com fotossensibilização e cinco com onfaloflebite). Os animais foram submetidos a colheitas diárias de sangue durante sete dias, enquanto internados no Hospital Veterinário da Unesp, Campus de Jaboticabal. Ceruloplasmina e haptoglobina apresentaram elevação significativa em animais acometidos por mastite, fotossensibilização e onfaloflebite $(275,17 \%$ e $343,71 \% ; 175,17 \%$ e $230,19 \% ; 114,47 \%$ e $144,47 \%$, respectivamente). A $\alpha_{1}$-glicoproteína ácida foi um bom biomarcador apenas em animais com mastite e fotossensibilização, elevando, respectivamente, suas concentrações séricas em 198,14\% e 145,89\%. Fibrinogênio mostrou-se um indicador confiável apenas em bovinos com mastite, com elevação de 146,5\% em relação ao grupo sadio. Ficou clara a diferença na responsividade de distintas PFAs frente a diferentes estímulos inflamatórios. Ceruloplasmina e haptoglobina foram biomarcadores mais sensíveis e, portanto, mais confiáveis entre as PFAs estudadas nessa espécie.

Palavras-chave: ceruloplasmina, fibrinogênio, haptoglobina, transferrina, glicoproteína ácida- $\alpha_{1}$

\begin{abstract}
Over the last few decades acute phase proteins (APP) have become the biomarkers of choice in human medicine to identify and monitor inflammation and infection. There is no reason to suppose that clinical investigations in veterinary medicine would not be equally assisted by APP assays. Aiming to verify the importance of APPs as biomarkers of inflammatory diseases in domestic cattle, serum protein profiles, especially APPs, were determined through the SDS-PAGE electrophoresis technique. Thirty animals were allotted in two groups: 15 healthy cattle and 15 clinically ill cattle (5 with staphylococcal mastitis, 5 with photosensitization and 5 with onphalophlebitis). All animals were submitted to daily blood sampling during 7 days, while interned in the Veterinarian Hospital from UNESP, Jaboticabal campus. Ceruloplasmin and haptoglobin were significantly elevated in animals with mastitis, photosensitization and onphalophlebitis (275.17\% and 343.71\%; $175.17 \%$ and $230.19 \% ; 114.47 \%$ and $144.47 \%$, respectively). $\alpha_{1}$-acid glycoprotein behaved as a good biomarker only in animals with mastitis and photosensitization, elevating respectively $198.14 \%$ and $145.89 \%$ of their serum levels. Fibrinogen was a reliable indicator only in animals undergoing mastitis, with a raise of $146.5 \%$. The diverse responsiveness of different APP under distinct inflammatory stimuli was clear. Ceruloplasmin and haptoglobin were more sensible and, therefore, reliable biomarkers to the diseases studied in this species.
\end{abstract}

Keywords: ceruloplasmin, fibrinogen, haptoglobin, transferrin, $\alpha_{1}$-acid glycoprotein

Recebido em 9 de março de 2012

Aceito em 12 de março de 2013

E-mail: kalinamms@hotmail.com 


\section{INTRODUÇÃO}

A crescente preocupação com a rapidez na identificação e resolução de problemas sanitários nos rebanhos aumentou o interesse no estudo de biomarcadores precoces no cenário da buiatria mundial. Pesquisas realizadas nas últimas décadas mostraram que a quantificação de proteínas de fase aguda (PFAs), no plasma ou no soro sanguíneo, pode ser útil tanto no diagnóstico, prognóstico e monitoramento de doenças quanto no bem-estar de indivíduos ou de rebanhos (Murata et al., 2004; González et al., 2007; Jain et al., 2011; Cray, 2012). Segundo Skinner (2001), pesquisas recentes sugerem que ensaios para a quantificação de PFAs serão utilizados rotineiramente no futuro, a fim de avaliar a saúde animal, otimizar o desempenho produtivo individual, monitorar a eficácia de terapias antibióticas, detectar doenças e, ainda, propiciar benefícios consideráveis à segurança alimentar, por meio da avaliação dos animais antes do abate.

A monitoração da resposta inflamatória pode ser um desafio clínico, pois nem sempre os sinais de inflamação se manifestam de modo evidente. Ganheim et al. (2003), em estudo com bovinos experimentalmente infectados pelo vírus da diarreia viral bovina e por Mannheimia haemolytica, relataram que, em vários momentos, os sinais clínicos foram muito sutis e que, portanto, a doença inflamatória/infecciosa passaria despercebida se não fossem mensuradas as PFAs, as quais se mostraram significativamente elevadas. Deste modo, o objetivo deste trabalho foi avaliar a importância das PFAs como biomarcadores de enfermidades inflamatórias de ocorrência natural, na espécie bovina.

\section{MATERIAL E MÉTODOS}

Os animais foram distribuídos em dois grupos: 15 bovinos sadios e 15 bovinos com doença aguda, sendo este último constituído por cinco animais com mastite estafilocócica, cinco com fotossensibilização hepatógena e cinco com onfaloflebite. $\mathrm{O}$ estudo foi aprovado pela Comissão de Ética e Bem-Estar Animal (Cebea) da Faculdade de Ciências Agrárias e Veterinárias (FCAV)/Unesp/Campus Jaboticabal, sob número de protocolo 029033-08.
A triagem dos animais foi efetuada após realização de exame físico (Dirksen et al., 1993), e, quando necessário, este foi complementado por exames auxiliares de diagnóstico. Os animais clinicamente sadios (controle) pertenciam ao rebanho da FCAV/Unesp/Campus de Jaboticabal, e os grupos de animais doentes foram constituídos por pacientes atendidos no Hospital Veterinário da mesma instituição. As vacas com mastite foram submetidas ao tratamento intramamário com gentamicina intramamária (Mastifin®, Ouro Fino, Brasil), uma vez ao dia, durante três dias. Os bovinos com fotossensibilização foram submetidos à dosagem de enzimas hepáticas, AST e GGT, para confirmação do diagnóstico e, então, recebiam, por via intravenosa, uma mistura de aminoácidos (Mercepton ${ }^{\circledR}$, complexo lipotrópico e antitóxico, Bravet, Brasil), sendo mantidos em ambiente sombreado; bezerros com onfaloflebite recebiam tratamento local com tintura de iodo a $2 \%$. Uma vez incluído no experimento, o animal era submetido a exame físico e colheita de sangue diária, durante seis dias, nominalmente identificados como momentos M1 (antes do início do tratamento), M2 (24h após tratamento), M3 (48h após tratamento), M4 (72h após tratamento), M5 (96h após tratamento) e M6 (120h após tratamento), respectivamente.

Para obtenção do soro, foram colhidas amostras de $10 \mathrm{~mL}$ de sangue em tubos sem anticoagulante; as alíquotas obtidas foram acondicionadas à temperatura de $-80^{\circ} \mathrm{C}$, para posterior análise laboratorial. A determinação da proteína total sérica foi realizada pelo método do biureto, empregando-se kit comercial (Labtest, Belo Horizonte, MG, Brasil). A concentração plasmática de fibrinogênio foi determinada segundo técnica da precipitação pelo calor, descrita por Jain (1993).

A separação das frações proteicas das amostras de soro sanguíneo foi realizada utilizando-se eletroforese em gel de poliacrilamida contendo dodecil sulfato de sódio (SDS-PAGE), conforme técnica descrita por Laemmli (1970). As concentrações dessas proteínas foram determinadas em densitômetro computadorizado (Shimadzu, Tóquio, Japão). Como referência, foi usada solução marcadora (Sigma, Saint Louis, EUA) com pesos moleculares 29.000, 45.000, 66.000, 97.400, 116.000 e 205.000 dáltons (D), 
além das proteínas purificadas transferrina, haptoglobina, ceruloplasmina e $\alpha_{1}$-antitripsina.

Os resultados foram analisados pelo programa ANOVA. Constatadas diferenças entre as médias, os valores foram comparados pelo teste de Tukey a 5\% de significância (Petrie e Watson, 2009).

\section{RESULTADOS E DISCUSSÃO}

Notou-se que a concentração sérica de proteína total de bovinos doentes e daqueles sadios não diferiu significativamente.

Nos bovinos com fotossensibilização, verificouse aumento significativo na concentração sérica de ceruloplasmina, de $175,17 \%$, em relação ao grupo sadio (Tab. 1 e Fig. 1). Fagliari et al. (2007) verificaram aumento do teor sérico de ceruloplasmina de $309,1 \%$ em animais com fotossensibilização hepatógena, quando comparado àquele de animais sadios. À semelhança do que constataram os autores supracitados, após o primeiro dia de estudo, a concentração sérica dessa proteína decresceu enquanto os animais eram submetidos a tratamento apropriado. Esse dado reafirma a utilidade da ceruloplasmina no monitoramento da recuperação do animal frente à terapia instituída. Vacas com mastite apresentaram as maiores concentrações séricas de ceruloplasmina, sendo constatado aumento de $275,17 \%$ em relação aos animais sadios, com posterior decréscimo, embora diminuição significativa só tenha sido observada no último momento experimental (M6). Ainda há poucos relatos sobre o comportamento dessa proteína em casos de mastite em vacas, entretanto Costa et al. (2010) observaram aumento de $297,86 \%$ na concentração sérica de ceruloplasmina em ovelhas com mastite estafilocócica experimental. Ambos os resultados podem ser justificados pela ação anti-inflamatória e biocatalisadora da ceruloplasmina. Preconiza-se que um aumento na atividade da ceruloplasmina oxidase em vacas com mastite seria reflexo da ativação de um mecanismo dependente da atividade desse complexo enzimático contra o estresse oxidativo em fêmeas afetadas. Essa resposta teria a função de compensar a ineficiência de outros mecanismos antioxidantes comprometidos (Patel et al., 2002). Quanto aos animais com onfaloflebite, constatou-se aumento de 114,54\% na concentração sérica de ceruloplasmina, com posterior decréscimo ao longo do tratamento. Embora a utilização da ceruloplasmina como marcador inflamatório seja menos comum que a de outras PFAs, como a haptoglobina (Murata et al., 2004), os resultados aqui expostos reforçam a importância desse biomarcador em doenças inflamatórias/infecciosas.

Tabela 1. Médias e desvios-padrão das concentrações séricas de ceruloplasmina (mg/dL) de bovinos sadios e bovinos portadores de doença inflamatória recente atendidos no HV da FCAV/Unesp/Campus de Jaboticabal, no dia da internação (M1) e nos cinco dias subsequentes (M2 a M6)

\begin{tabular}{lcccccc}
\hline \multicolumn{1}{c}{ Grupo } & \multicolumn{5}{c}{ Momento } \\
\cline { 2 - 7 } & M1 & M2 & M3 & M4 & M5 & M6 \\
\hline Grupo sadio & $14,1 \pm 4,11 \mathrm{Aa}$ & $16,6 \pm 3,54 \mathrm{Aa}$ & $13,9 \pm 3,03 \mathrm{Aa}$ & $15,9 \pm 4,10 \mathrm{Aa}$ & $12,8 \pm 3,88 \mathrm{Aa}$ & $16,1 \pm 4,23 \mathrm{Aa}$ \\
Grupo doente & & & & & & \\
Fotossensibilização & $49,2 \pm 7,13 \mathrm{Ba}$ & $44,5 \pm 6,65 \mathrm{Bab}$ & $40,3 \pm 7,01 \mathrm{Bb}$ & $40,0 \pm 6,76 \mathrm{Bb}$ & $37,2 \pm 6,11 \mathrm{Bb}$ & $34,8 \pm 5,74 \mathrm{Bb}$ \\
Mastite & $62,6 \pm 9,23 \mathrm{Ca}$ & $60,2 \pm 8,56 \mathrm{Ca}$ & $58,9 \pm 9,87 \mathrm{Ca}$ & $55,6 \pm 7,98 \mathrm{Ca}$ & $50,7 \pm 8,09 \mathrm{Cab}$ & $47,4 \pm 6,61 \mathrm{Cb}$ \\
Onfaloflebite & $36,7 \pm 5,04 \mathrm{Da}$ & $34,8 \pm 6,13 \mathrm{Da}$ & $33,0 \pm 5,22 \mathrm{Dab}$ & $29,9 \pm 4,99 \mathrm{Db}$ & $30,3 \pm 5,41 \mathrm{Db}$ & $27,1 \pm 4,23 \mathrm{Db}$ \\
\hline
\end{tabular}

Médias seguidas de letras maiúsculas iguais, na mesma coluna, e letras minúsculas iguais, na mesma linha, não diferem entre si pelo teste Tukey $(\mathrm{P}>0,05)$.

Quanto às concentrações séricas de transferrina, observou-se, de forma geral, diminuição inicial em todos os animais doentes, com posterior elevação ao longo do período de estudo (Tab. 2 e Fig. 2). No entanto, os valores séricos dessa proteína só foram significativamente menores em relação ao grupo sadio em bovinos com mastite, os quais, a partir do quinto dia de avaliação (M5), apresentaram elevação das suas concentrações séricas, assemelhando-se às concentrações dos animais sadios. Essa diminuição dos teores séricos de transferrina observada nos primeiros momentos do estudo a caracterizam como proteína de fase aguda 
negativa, conforme descrito por Jain et al. (2011). A redução dessa PFA representa um mecanismo de defesa do organismo, considerando que essa proteína sequestra íons férricos, que podem servir como substrato para diversos microrganismos (Murata et al., 2004).
Para Tizard (2002), a concentração de transferrina aumenta quando há diminuição do teor sérico de ferro, situação que pode ocorrer em infecções causadas por $S$. aureus, que necessita desse mineral para sua multiplicação.

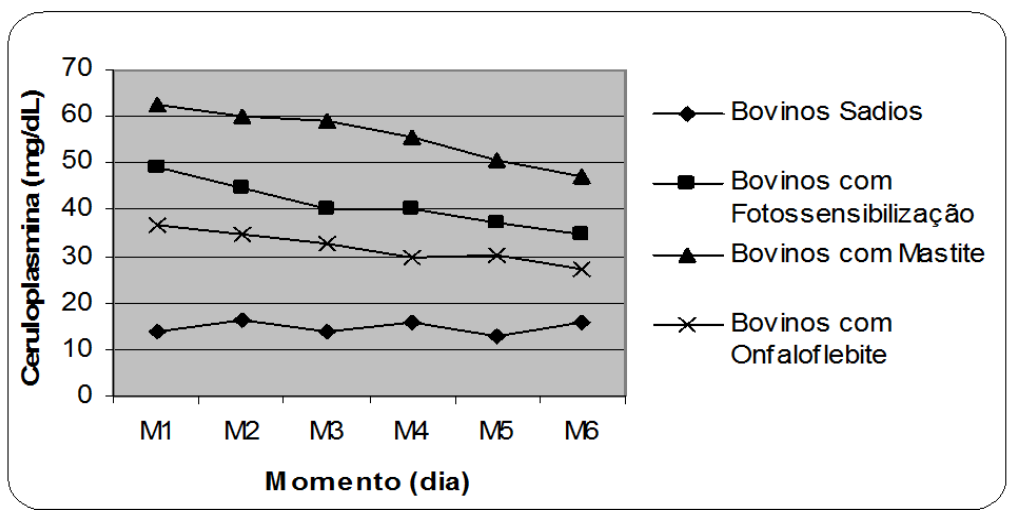

Figura 1. Médias das concentrações séricas de ceruloplasmina (mg/dL) de bovinos sadios e bovinos com fotossensibilização, mastite ou onfaloflebite, no dia da internação (M1) e nos cinco dias subsequentes (M2 a M6).

Tabela 2. Médias e desvios-padrão das concentrações séricas de transferrina (mg/dL) de bovinos sadios e bovinos portadores de doença inflamatória recente atendidos no HV da FCAV/Unesp/Campus de Jaboticabal, no dia da internação (M1) e nos cinco dias subsequentes (M2 a M6)

\begin{tabular}{|c|c|c|c|c|c|c|}
\hline Grupo & \multicolumn{6}{|c|}{ Momento } \\
\hline Grupo sadio & $253 \pm 22,0 \mathrm{Aa}$ & $268 \pm 19,9 \mathrm{Aa}$ & $258 \pm 20,3 \mathrm{Aa}$ & $270 \pm 24,6 \mathrm{Aa}$ & $264 \pm 23,6 \mathrm{Aa}$ & $260 \pm 20,66 \mathrm{Aa}$ \\
\hline Fotossensibilização & $248 \pm 29,3 \mathrm{ABa}$ & $246 \pm 30,5 \mathrm{ABa}$ & $251 \pm 23,7 \mathrm{ABa}$ & $258 \pm 26,9 \mathrm{Aa}$ & $260 \pm 31,1 \mathrm{Aa}$ & $255 \pm 25,8 \mathrm{Aa}$ \\
\hline Mastite & $226 \pm 22,5 \mathrm{Ba}$ & $240 \pm 26,7 \mathrm{Ba}$ & $234 \pm 19,8 \mathrm{Ba}$ & $240 \pm 21,5 \mathrm{Ba}$ & $247 \pm 23,2 \mathrm{Aa}$ & $260 \pm 30,5 \mathrm{Aa}$ \\
\hline
\end{tabular}

Médias seguidas de letras maiúsculas iguais, na mesma coluna, e letras minúsculas iguais, na mesma linha, não diferem entre si pelo teste Tukey $(\mathrm{P}>0,05)$.

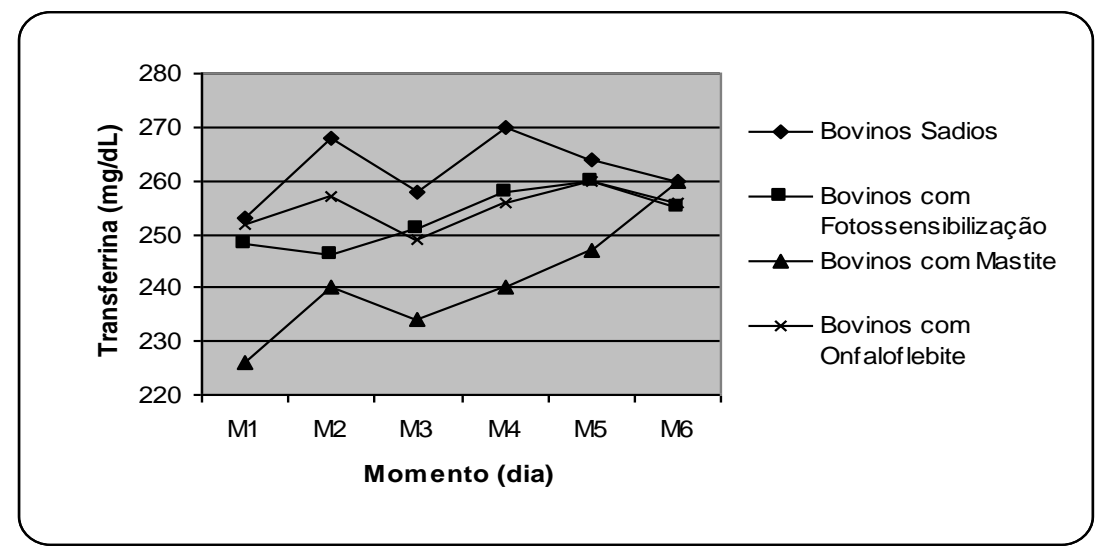

Figura 2. Médias das concentrações séricas de transferrina $(\mathrm{mg} / \mathrm{dL})$ de bovinos sadios e bovinos com fotossensibilização, mastite ou onfaloflebite, no dia da internação (M1) e nos cinco dias subsequentes (M2 a M6). 
Nos bovinos acometidos por fotossensibilização, registrou-se elevação nas concentrações séricas de haptoglobina de 230,19\% em relação ao grupo sadio (Tab. 3 e Fig. 3). Esse aumento corrobora o observado por Fagliari et al. (2007), em estudo com bovinos acometidos por fotossensibilização induzida experimentalmente, no qual os autores citaram que a haptoglobina foi a PFA cujo aumento sérico foi o mais marcante em relação a outras PFAs avaliadas, entre elas ceruloplasmina e $\alpha_{1}$-glicoproteína ácida. Os autores concluíram ainda que ensaios para a mensuração de PFAs, como a haptoglobina, podem ser úteis tanto para acompanhar a resposta do animal quanto para orientar uma possível mudança no protocolo terapêutico. Esse fato também foi constatado no presente trabalho, no qual foi possível observar o declínio do teor de ceruloplasmina acompanhado pela resposta positiva dos animais após instituição de terapia apropriada. As concentrações séricas de haptoglobina atingiram valores significativamente menores apenas no último dia de estudo (M6), embora ainda tenham se mantido significativamente elevadas em relação aos animais sadios, reforçando o que cita a literatura quanto à marcante resposta dos bovinos no que tange a elevações nos níveis dessa proteína frente a estímulos inflamatórios, sendo, consequentemente, uma das PFAs mais estudadas nessa espécie (Hirvonen e Pyörälä, 1998).

Os bovinos com mastite apresentaram a maior concentração sérica de haptoglobina entre os doentes, um aumento de $343,71 \%$, atingindo valor máximo no terceiro dia de internação (M3), com posterior decréscimo, corroborando os achados de Suojala et al. (2008), que, embora tenham realizado estudo experimental, observaram igualmente elevação dos níveis de haptoglobina após infecção intramamária. Já foram registrados aumentos relevantes nos teores dessa proteína em vacas acometidas por mastite de ocorrência natural, bem como correlação positiva entre a contagem de células somáticas e a concentração sérica de haptoglobina (Colla et al., 2011). Ainda, Colla et al. (2011) ressaltaram o valor diagnóstico da haptoglobina em casos de mastite subclínica em vacas leiteiras, sublinhando a correlação positiva existente entre a severidade da lesão e os níveis séricos dessa proteína. Da mesma forma, Singh e Pachauri (2002) concluíram haver correlação direta entre o seu teor plasmático e a extensão da lesão no tecido mamário.

Nos bovinos com onfaloflebite, a concentração sérica de haptoglobina elevou-se em 144,47\%, como mostram a Tab.3 e a Fig. 3 .

Em bovinos com fotossensibilização hepatógena, notou-se elevação de 145,89\% na concentração sérica de $\alpha_{1}$-glicoproteína ácida (Tab. 4 e Fig. 4). Fagliari et al. (2007) também constataram aumento significativo na concentração sérica dessa PFA em bovinos acometidos por fotossensibilização. À semelhança dos resultados aqui apresentados, os autores relataram aumento de $146,2 \%$, em comparação a bovinos sadios.

Tabela 3. Médias e desvios-padrão das concentrações séricas de haptoglobina (mg/dL) de bovinos sadios e bovinos portadores de doença inflamatória recente atendidos no HV da FCAV/Unesp/Campus de Jaboticabal, no dia da internação (M1) e nos cinco dias subsequentes (M2 a M6)

\begin{tabular}{lcccccc}
\hline \multirow{2}{*}{ Grupo } & \multicolumn{5}{c}{ Momento } \\
\cline { 2 - 7 } & M1 & M2 & M3 & M4 & M5 & M6 \\
\hline Grupo sadio & $35,1 \pm 5,11 \mathrm{Aa}$ & $38,1 \pm 4,73 \mathrm{Aa}$ & $33,6 \pm 3,91 \mathrm{Aa}$ & $37,4 \pm 4,02 \mathrm{Aa}$ & $32,0 \pm 3,74 \mathrm{Aa}$ & $36,1 \pm 4,15 \mathrm{Aa}$ \\
Grupo doente & & & & & & \\
Fotossensibilização & $123 \pm 20,7 \mathrm{Ba}$ & $127 \pm 22,34 \mathrm{Ba}$ & $120 \pm 25,2 \mathrm{Ba}$ & $114 \pm 19,9 \mathrm{Ba}$ & $111 \pm 17,3 \mathrm{Ba}$ & $106 \pm 10,2 \mathrm{Bb}$ \\
Mastite & $159 \pm 26,2 \mathrm{Ca}$ & $165 \pm 23,8 \mathrm{Ca}$ & $170 \pm 19,7 \mathrm{Ca}$ & $161 \pm 17,4 \mathrm{Ca}$ & $149 \pm 16,1 \mathrm{Cb}$ & $138 \pm 15,8 \mathrm{Cb}$ \\
Onfaloflebite & $94 \pm 10,5 \mathrm{Da}$ & $90 \pm 12,3 \mathrm{Dab}$ & $85 \pm 10,7 \mathrm{Dab}$ & $89 \pm 9,8 \mathrm{Dab}$ & $82 \pm 11,5 \mathrm{Db}$ & $79 \pm 9,2 \mathrm{Db}$ \\
\hline
\end{tabular}

Médias seguidas de letras maiúsculas iguais, na mesma coluna, e letras minúsculas iguais, na mesma linha, não diferem entre si pelo teste Tukey $(\mathrm{P}>0,05)$. 


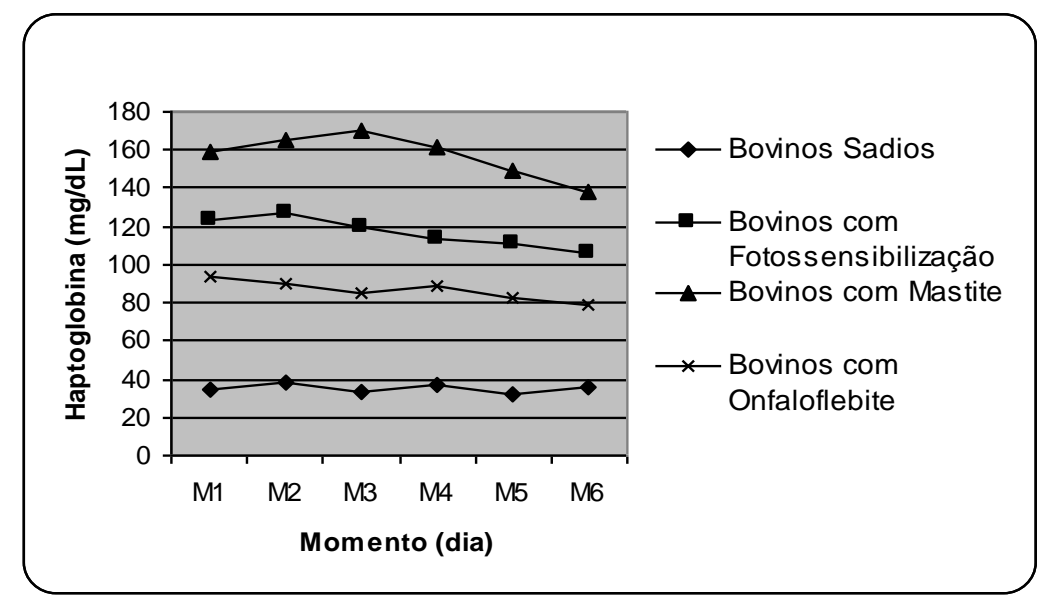

Figura 3. Médias das concentrações séricas de haptoglobina $(\mathrm{mg} / \mathrm{dL})$ de bovinos sadios e bovinos com fotossensibilização, mastite ou onfaloflebite, no dia da internação (M1) e nos cinco dias subsequentes (M2 a M6).

Tabela 4. Médias e desvios-padrão das concentrações séricas de al-glicoproteína ácida (mg/dL) de bovinos sadios e bovinos portadores de doença inflamatória recente atendidos no $\mathrm{HV}$ da FCAV/Unesp/Campus de Jaboticabal, no dia da internação (M1) e nos cinco dias subsequentes (M2 a M6)

\begin{tabular}{ccccccc}
\hline \multirow{2}{*}{ Grupo } & \multicolumn{5}{c}{ Momento } \\
\cline { 2 - 7 } & M1 & M2 & M3 & M4 & M5 & M6 \\
\hline Grupo sadio & $13,9 \pm 2,4 \mathrm{Aa}$ & $16,0 \pm 2,1 \mathrm{Aa}$ & $14,7 \pm 1,7 \mathrm{Aa}$ & $17,1 \pm 1,9 \mathrm{Aa}$ & $15,8 \pm 2,0 \mathrm{Aa}$ & $13,8 \pm 1,8 \mathrm{Aa}$ \\
Grupo doente & & & & & & \\
Fotossensibilização & $39,1 \pm 4,8 \mathrm{Ba}$ & $40,3 \pm 5,2 \mathrm{Ba}$ & $38,4 \pm 4,9 \mathrm{Ba}$ & $35,2 \pm 5,3 \mathrm{Bab}$ & $37,2 \pm 4,4 \mathrm{Bab}$ & $34,3 \pm 3,8 \mathrm{Bb}$ \\
Mastite & $44,2 \pm 5,5 \mathrm{Ca}$ & $49,0 \pm 4,7 \mathrm{Cb}$ & $52,8 \pm 6,3 \mathrm{Cb}$ & $47,0 \pm 5,1 \mathrm{Cb}$ & $40,0 \pm 4,8 \mathrm{Ca}$ & $39,2 \pm 5,1 \mathrm{Ca}$ \\
Onfaloflebite & $15,4 \pm 2,97 \mathrm{Aa}$ & $17,3 \pm 2,84 \mathrm{Aa}$ & $16,2 \pm 2,43 \mathrm{Aa}$ & $14,1 \pm 2,12 \mathrm{Aa}$ & $15,1 \pm 1,95 \mathrm{Aa}$ & $14,8 \pm 2,22 \mathrm{Aa}$ \\
\hline
\end{tabular}

Médias seguidas de letras maiúsculas iguais, na mesma coluna, e letras minúsculas iguais, na mesma linha, não diferem entre si pelo teste Tukey $(\mathrm{P}>0,05)$.

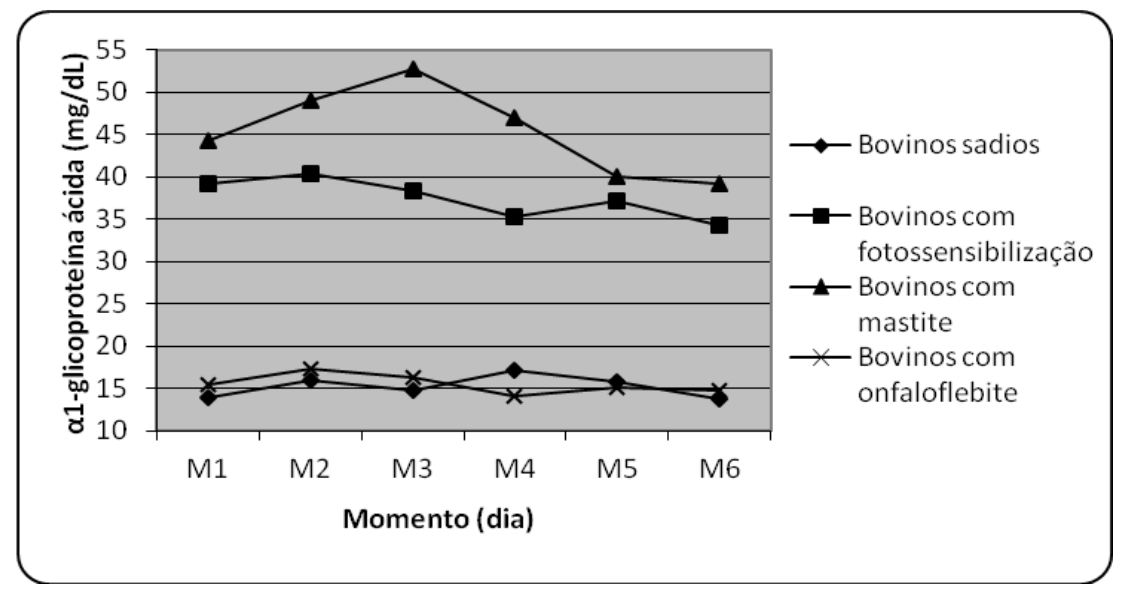

Figura 4. Médias das concentrações séricas de $\alpha_{1}$-glicoproteína ácida $(\mathrm{mg} / \mathrm{dL})$ de bovinos sadios e bovinos com fotossensibilização, mastite ou onfaloflebite, no dia da internação (M1) e nos cinco dias subsequentes (M2 a M6). 
Os animais com mastite apresentaram valores médios de $\alpha_{1}$-glicoproteína ácida superiores ao grupo sadio durante todo o período experimental, sendo observado um aumento de $198,14 \%$ nas concentrações séricas dessa proteína. Tal resultado ratifica as afirmações de Murata et al. (2004), que consideram essa proteína um importante biomarcador no monitoramento clínico de processos inflamatórios em bovinos. Entretanto, Alsemgeest et al. (1995), ao compararem reações inflamatórias agudas e crônicas em bovinos, concluíram que a $\alpha 1$ glicoproteína ácida está mais associada a condições crônicas. Mais estudos devem ser feitos acerca da atuação dessa PFA positiva em casos de mastite.

Ao contrário dos animais com fotossensibilização ou mastite, nos quais a $\alpha_{1}$ glicoproteína ácida foi biomarcador sensível de inflamação, nos bovinos com onfaloflebite não foi verificada diferença significativa nas concentrações séricas de $\alpha_{1}$-glicoproteína ácida em relação ao grupo sadio, corroborando Hirvonen (2000), que afirmou que a $\alpha 1$-glicoproteína ácida possui resposta moderada a relativamente baixa em resposta à injúria tecidual em bovinos.

Nos bovinos acometidos por fotossensibilização, observou-se discreto aumento nas concentrações plasmáticas de fibrinogênio em relação aos animais sadios, de 8,68\% (Tab. 5 e Fig. 5). Embora as concentrações plasmáticas dessa proteína não tenham excedido o limite de referência largamente utilizado na rotina clínica veterinária, estabelecido por Kaneko et al. (2007), neste estudo todos os animais doentes apresentaram valores significativamente elevados em relação ao grupo sadio.

Tabela 5. Médias e desvios-padrão das concentrações plasmáticas de fibrinogênio (mg/dL) de bovinos sadios e bovinos portadores de doença inflamatória recente atendidos no HV da FCAV/Unesp/Campus de Jaboticabal, no dia da internação (M1) e nos cinco dias subsequentes (M2 a M6)

\begin{tabular}{ccccccc}
\hline \multirow{2}{*}{ Grupo } & \multicolumn{5}{c}{ Momento } \\
\cline { 2 - 7 } & M1 & M2 & M3 & M4 & M5 & M6 \\
\hline Grupo sadio & $364 \pm 32,8 \mathrm{Aa}$ & $356 \pm 36,2 \mathrm{Aa}$ & $377 \pm 33,9 \mathrm{Aa}$ & $364 \pm 30,5 \mathrm{Aa}$ & $359 \pm 32,0 \mathrm{Aa}$ & $380 \pm 29,8 \mathrm{Aa}$ \\
Grupo doente & & & & & & \\
Fotossensibilização & $422 \pm 43,2 \mathrm{Bab}$ & $405 \pm 37,7 \mathrm{Bab}$ & $401 \pm 34,6 \mathrm{Bab}$ & $395 \pm 31,0 \mathrm{Bab}$ & $388 \pm 27,6 \mathrm{Bab}$ & $380 \pm 31,3 \mathrm{Bb}$ \\
Mastite & $964 \pm 91,4 \mathrm{Ca}$ & $973 \pm 97,6 \mathrm{Ca}$ & $939 \pm 90,6 \mathrm{Ca}$ & $922 \pm 84,3 \mathrm{Ca}$ & $822 \pm 79,5 \mathrm{Cb}$ & $804 \pm 76,8 \mathrm{Cb}$ \\
Onfaloflebite & $501 \pm 45,7 \mathrm{Da}$ & $522 \pm 50,1 \mathrm{Da}$ & $498 \pm 41,9 \mathrm{Dab}$ & $505 \pm 49,5 \mathrm{Da}$ & $483 \pm 40,1 \mathrm{Dab}$ & $459 \pm 40,3 \mathrm{Db}$ \\
\hline
\end{tabular}

Médias seguidas de letras maiúsculas iguais, na mesma coluna, e letras minúsculas iguais, na mesma linha, não diferem entre si pelo teste Tukey $(\mathrm{P}>0,05)$.

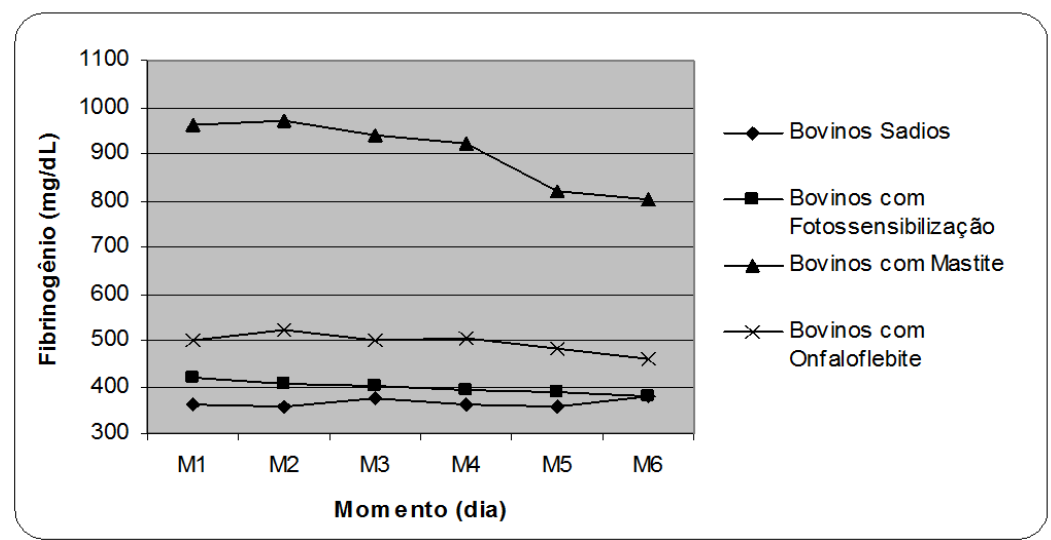

Figura 5. Médias das concentrações séricas de fibrinogênio $(\mathrm{mg} / \mathrm{dL})$ de bovinos sadios e bovinos com fotossensibilização, mastite ou onfaloflebite, no dia da internação (M1) e nos cinco dias subsequentes (M2 a M6). 
Os bovinos com mastite apresentaram uma elevação de $146,5 \%$ nas concentrações plasmáticas de fibrinogênio, decrescendo ao longo do experimento. Nielsen et al. (2004) ressaltaram uma elevação mais marcante no teor de fibrinogênio de vacas com mastite em relação a vacas com condições inflamatórias extramamárias, assim como foi constatado nos resultados aqui apresentados, ao se compararem os dados referentes aos bovinos com mastite e aqueles acometidos por fotossensibilização ou onfaloflebite. Isto possivelmente ocorreu devido ao fato de as vacas com mastite estarem sujeitas a estímulo inflamatório mais severo. Colla et al. (2011) também constataram elevação nas concentrações plasmáticas de fibrinogênio em vacas com mastite clínica e subclínica quando comparadas a animais saudáveis. No entanto, estes autores concluíram que o fibrinogênio não foi sensível em discriminar animais com mastite clínica daqueles com processo subclínico em curso.

Nos bovinos com onfaloflebite, as concentrações plasmáticas de fibrinogênio também foram superiores às dos animais sadios, com elevação de $34,91 \%$, decrescendo posteriormente. A resposta apresentada pelo grupo doente neste estudo mostrou a precocidade e persistência da elevação do teor plasmático de fibrinogênio por quanto tempo o estímulo inflamatório seja mantido. $\mathrm{O}$ fato de os animais doentes só apresentarem redução das concentrações plasmáticas dessa proteína alguns dias após o início do experimento - levando-se em conta o tempo transcorrido entre o real início do processo de injúria tissular e o primeiro dia de internação - confirma os relatos de Cole et al. (1997) quanto à persistência na elevação da concentração plasmática dessa PFA durante o processo patológico pelo tempo em que ele permaneça ativo, retornando aos níveis fisiológicos paulatinamente, em alguns dias ou até semanas, ao contrário de outras PFAs.

Diante dos resultados obtidos, é possível inferir que ceruloplasmina e haptoglobina atuaram como biomarcadores precoces e confiáveis em bovinos acometidos por mastite estafilocócica, fotossensibilização hepatógena ou onfaloflebite, enquanto $\alpha_{1}$-glicoproteína ácida mostrou boa responsividade apenas para animais fotossensibilizados e mastíticos. Fibrinogênio foi um bom indicador de foco inflamatório apenas em bovinos sofrendo de mastite estafilocócica. Essa diferença na responsividade de diferentes PFAs para distintas enfermidades confirma dados já citados na literatura, nos quais se explica que a síntese proteica é estabelecida geneticamente, o que justificaria essa variabilidade entre espécies e indivíduos, a qual é refletida no perfil eletroforético das proteínas séricas em situação fisiológica (Kaneko et al., 2007; Eckersall e Conner, 1988; Eckersall, 2004). O comportamento variável de uma mesma PFA em diferentes enfermidades foi descrito por Baumann et al. (1989), os quais demonstraram que combinações diferentes de citocinas - entre elas IL-1, IL-6, IL-8, IL-10 e FNT $\alpha$ - induzem a produção de diferentes PFAs em hepatócitos de ratos. Conner et al. (1988) salientaram ainda que nem todas as PFAs são igualmente sensíveis e rápidas quanto a sua resposta a um "fator desencadeante". Portanto, é esperado que cada proteína reaja distintamente para cada tipo de enfermidade, sendo necessárias cada vez mais pesquisas envolvendo diferentes tipos de doenças.

\section{CONCLUSÕES}

A diferença na responsividade de distintas PFAs frente a diferentes estímulos inflamatórios ficou clara diante dos resultados obtidos. Das PFAs analisadas, ceruloplasmina e haptoglobina mostraram-se biomarcadores precoces e confiáveis na espécie bovina, independentemente da enfermidade avaliada.

\section{AGRADECIMENTOS}

À Fundação de Apoio e Amparo à Pesquisa do Estado de São Paulo (Fapesp), pelo financiamento deste projeto.

\section{REFERÊNCIAS}

ALSEMGEEST, S.P.M.; LAMBOOY, I.E.; WIERENGA, H.K. et al. Influence of physical stress on the plasma concentration of serum amyloid A (SAA) and haptoglobin (HP) in calves. Vet. Quat., v.17, p.9-12, 1995.

BAUMANN, H.; PROWSE, K.R.; MARINKOVIC, S. et al. Stimulation of hepatic acute phase response by cytokines and glucocorticoids. 1989. Disponível em <http://onlinelibrary. wiley.com/doi/10.1111/j.17496632.1989.tb24021.x/abstract> Acessado em: 13 dez. 2011. 
COLE, D.J.; ROUSSEL, A.J.; WHITNEY, M.S. Interpreting a bovine $\mathrm{CBC}$ : evaluating the leukon and acute-phase proteins. Food Anim. Prac., v.92, p.470478, 1997.

COLLA, M.F.; VALLE, S.F.; SECCHI, P. et al. Plasma haptoglobin values in cows with different somatic cell counting in milk samples. Acta Sci. Vet., v.39, p.739-743, 2011.

CONNER, J.G.; ECKERSALL, P.D.; WISEMAN, A. et al. Bovine acute phase response following turpentine injection. Res. Vet. Sci., v.44, p.82-88, 1988.

COSTA, N.A.; SIMÃO, L.C.V.; SANTOS, R.A. et al. Proteinograma e teores de cobre, ferro e zinco no soro sanguíneo de ovelhas da raça Santa Inês com mastite experimental por Staphylococcus aureus. Pesq. Vet. Bras., v.30, p.435-442, 2010.

CRAY, C. Acute phase proteins in animals. Prog. Mol. Bio. Transl. Sci., v.105, p.113-150, 2012.

DIRKSEN, G.; GRÜNDER, H.; GRUNERT, E. et al. 3.ed. Rosenberger: Exame clínico de ruminantes. Guanabara Koogan, 1993. 419p.

ECKERSALL, P.D. The time is right for acute phase proteins assays. Brit. Vet. J., London, v.168, p.3-5, 2004.

ECKERSALL, P.D.; CONNER, J.G. Bovine and canine acute phase proteins. Vet. Res. Com. v.12, p.169-178, 1988.

FAGLIARI, J.J.; PASSIPIERI, M.; OKUDA, H.T. et al. Serum protein concentrations, including acute phase proteins, in calves with hepatogenous photosensitization. Arq. Bras. Med. Vet. Zoot., v.59, p.1355-1358, 2007.

GANHEIM, C.; HULTÉN, C.; CARLSSON, U. et al. The acute phase response in calves experimentally infected with bovine viral diarrhea virus and/or Mannheimia haemolytica. J. Vet. Med., v.50, p.183190, 2003.

GONZÁLEZ, F.H.D.; MARTÍNEZ-SUBIELA， S.; CERÓN, J.J. Haptoglobina en rumiantes: generalidades y posibles aplicaciones clínicas. Anal. Vet. Mur., v.23, p.5-17, 2007.

HIRVONEN, J. Acute phase response in dairy cattle. 2000. 80f. Dissertação (Master's degree) - Faculty of Veterinary Medicine, University of Helsinki, Helsinky, Finland.
HIRVONEN, J.; PYÖRÄLÄ, S. Acute phase response in dairy cows with surgically-treated abdominal disorders. Vet. J., v.155, p.53-61, 1998.

JAIN, N.C. Essentials of Veterinary Hematology. Philadelphia: Lea \& Febinger, 1993. 417p.

JAIN, S.; GAUTAM, V.; NASEEM, S. Acute phase proteins: As diagnostic tool. J Pharm. Bioal. Sci., v.3, p.118-127. 2011.

KANEKO, J.J.; HARVEY, J.W.; BRUSS, M.L. 6.ed. Clinical biochemistry of domestic animals. New York: Academic Press, 2007. 1000p.

LAEMMLI, U.K. Cleavage of structural proteins during the assembly of the head of bacteriophage T4. Nat., v.227, p.680-685, 1970.

MURATA, H.; SHIMADA, N.; YOSHIOKA, M. Current research on acute phase proteins in veterinary diagnosis: an overview. Vet. J., v.168, p.28-40, 2004.

NIELSEN, B.H.; JACOBSEN, S.; ANDERSEN, P.H. et al. Acute phase protein concentrations in serum and milk from healthy cows, cows with clinical mastitis and cows with extramammary inflammatory conditions. Vet. Rec., v.154, p.361-365, 2004.

PATEL, B.N.; DUNN, R.J.; JEONG, S.Y. et al. Ceruloplasmin regulates iron levels in the CNS and prevents free radical injury. J. Neurosci., v.22, p.6578$6586,2002$.

PETRIE, A.; WATSON, P. Estatística em ciência animal e veterinária. 2.ed. São Paulo: Roca, 2009. 236p.

SINGH, S.V; PACHAURI, S.P. Acute phase proteins in bovine mastitis. Ind. J. Ani. Sci., v.72, p.20-22, 2002

SKINNER, J.G. International standardization of acute phase proteins. Special Report. Vet. Clin. Pat., v.30, p.2-7, 2001.

SUOJALA, L.; ORRO, T.; JARVINEN, H. et al. Acute phase response in two consecutive experimentally induced $E$. coli intramammary infections in dairy cows. Acta. Vet. Scand., v.50, p.110, 2008.

TIZARD, I.R. Imunologia Veterinária: uma introdução. 6.ed. São Paulo: Roca, 532p. 2002. 